\title{
Maternal Sociodemographic and Health Behaviours Associated with Adiposity in Infants as Measured by Air Displacement Plethysmography.
}

\author{
A. Bennett \\ Technological University Dublin
}

Follow this and additional works at: https://arrow.tudublin.ie/scschbioart

Part of the Biology Commons

\section{Recommended Citation}

Bennett, A., Kearney, J. (2019). Maternal sociodemographic and health behaviours associated with adiposity in infants as measured by air displacement plethysmography. Early Human Developmentvol.140. doi:10.1016/j.earlhumdev.2019.104887

This Article is brought to you for free and open access by the School of Biological Sciences at ARROW@TU Dublin. It has been accepted for inclusion in Articles by an authorized administrator of ARROW@TU Dublin. For more information, please contact arrow.admin@tudublin.ie, aisling.coyne@tudublin.ie,gerard.connolly@tudublin.ie. Funder: Technological Unversity Dublin

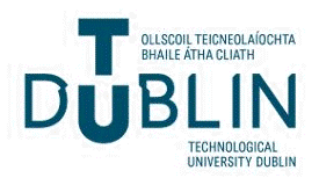




\title{
Maternal sociodemographic and health behaviours associated with adiposity in infants as measured by air displacement plethysmography
}

\author{
Annemarie E. Bennett ${ }^{\mathrm{a}, *}$, John M. Kearney ${ }^{\mathrm{b}}$

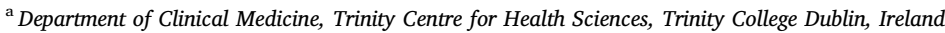 \\ ${ }^{\mathrm{b}}$ School of Biological and Health Sciences, Technological University Dublin, City Campus, Dublin, Ireland
}

\section{A R T I C L E I N F O}

\section{Keywords:}

Body composition

Infancy

Maternal body mass index

Air displacement plethysmography

Overweight

Obesity

\begin{abstract}
A B S T R A C T
Background: Identifying modifiable factors associated with body fat in infancy may improve health outcomes. Few studies have examined factors associated with percentage body fat calculated using air displacement plethysmography, a gold standard technique.

Aims: To investigate maternal sociodemographic and health behaviour characteristics associated with percentage body fat in offspring at birth.

Study design: Observational cross-sectional study in which the body composition of term infants was measured by air displacement plethysmography during the hospital stay after birth.

Subjects: One-hundred-and-ninety-six women and their term (37-42 weeks) infants.

Outcome measures: Associations between infant body composition and maternal sociodemographic and health characteristics.

Results: One-hundred-and-ninety-six women (41.8\% primiparous) participated. Mean percentage body fat among infants $(51.5 \%$ female) was $10.3 \pm 3.7$. Percentage body fat was significantly $(p<0.001)$ higher in infants born to women with an obese or overweight body mass index (BMI), when compared to infants born to women with a healthy BMI (12.1 \pm 4.0, $11.1 \pm 3.1$, and $9.2 \pm 3.7$, respectively). A significant positive correlation ( $r=0.294$ ) was observed, with the percentage body fat of infants born to women with an overweight or obese BMI being $17.1 \%$ and $23.9 \%$ higher, respectively, than that of infants born to women with a healthy weight BMI. Percentage body fat was lower in infants born to primiparous women $(p=0.011)$ and women of low social class $(p=0.003)$.

Conclusions: Infants born to women with an overweight or obese pre-pregnancy BMI had significantly higher mean percentage body fat when compared to infants born to women with a healthy pre-pregnancy BMI. Research into approaches that promote a healthy BMI in advance of pregnancy is warranted.
\end{abstract}

\section{Introduction}

Percentage body fat at birth is a sensitive biomarker of development in utero [1,2]. It is a better indicator of the quality of infant growth when compared with birth weight alone [3], and it may be an antecedent for obesity and other chronic diseases throughout life $[4,5]$. Given that a mother provides the intrauterine environment in which a foetus develops, it is expected that an infant's body composition at birth will reflect the physical condition of their mother during pregnancy $[6,7]$. Indeed, various maternal socio-demographic and health behaviour characteristics have been associated with birth weight and adiposity in the infant, including socioeconomic status [8], smoking $[9,10]$, hyperglycaemia [11], gestational diabetes [1,2,11], and an overweight or obese body mass index (BMI) $[2,3,6,7,11,12]$.
The reliable measurement of body fat at birth has been facilitated by air displacement plethysmography, a gold standard method for measuring neonatal body composition [4,13-17]. This method was used to determine normative values for percentage body fat at birth among a population-based cohort in Ireland, where values among males, females and the full sample of 743 infants were reported as $9.8 \%, 11.9 \%$ and $10.8 \%$, respectively [18]. With the availability of reliable measures of body composition in early infancy, researchers have the opportunity to explore further the association between maternal health and this critical facet of development in utero. Insights into modifiable factors associated with percentage body fat in infancy can pave the way for more effective health promotion among women and improved monitoring of infant growth from birth.

This study aimed to investigate maternal sociodemographic and

\footnotetext{
* Corresponding author.

E-mail address: abennet@tcd.ie (A.E. Bennett).
} 
health behaviour characteristics associated with body fat in offspring at birth, as measured by the gold standard method of air displacement plethysmography, and within an Irish context.

\section{Material and methods}

Ethical approval (GEN31413) was obtained from the Coombe Women and Infants University Hospital and Dublin Institute of Technology.

\subsection{Inclusion and exclusion criteria}

Women were eligible for inclusion if they had a healthy singleton pregnancy of at least 24 weeks gestation and were willing to be followed-up in hospital after giving birth to a term infant (37-42 weeks gestation). Due to the study sample size, only Caucasian women of Irish or British nationality were included to limit possible ethnic- and culturally- mediated confounding.

\subsection{Recruitment}

A convenience sample of women were recruited into the study whilst they waited in semi-private and public antenatal clinics in the Coombe Women and Infants University Hospital. Women who were at least 24 weeks pregnant were invited to consider the study information leaflet and to ask questions before written consent was obtained.

\subsection{Collection of maternal sociodemographic and health characteristic data}

A questionnaire was administered in the clinic for participants to self-complete. This questionnaire collected data on sociodemographic characteristics and health behaviours, to include: age; nationality; parity; education level; employment status; level of deprivation; marital status; planned pregnancy; folic acid supplementation practices; smoking status; and, alcohol intake. Maternal BMI [19] was recorded from the medical chart. It had been calculated at the first antenatal visit, where a midwife measured weight and height using calibrated scales and a stadiometer, respectively. BMI in the first trimester is an acceptable proxy for pre-pregnancy BMI, since weight gain is minimal in the first trimester [20-22].

\subsection{Collection of birth and infant feeding data}

Data recorded after birth included: type of delivery; gender; birth weight; and, feeding method initiated.

\subsection{Measurement of infant anthropometry}

A disposable paper medical tape (Henley's Medical Supplies Ltd., Hertfordshire, UK) was used to measure the circumference of each infant's head, chest, abdomen, mid-arm and mid-thigh. For all measurements, infants were in a supine position and the tape was held firmly but the skin was not compressed. All measurements were recorded to the nearest millimetre.

To measure head circumference, the tape was placed on the forehead, midway between the eyebrows and hairline, and fitted around the widest part of the back of the head over the occipital prominence. To measure chest circumference, the tape was placed midway between the infant's nipples and fitted around their chest whilst keeping the tape level. To measure abdominal circumference, the tape was placed just above the infant's navel and fitted around their abdomen whilst keeping the tape level. To measure mid-arm circumference, the tape was fitted midway between the olecranon process of the ulna and the acromion process of the scapula. To measure mid-thigh circumference, the measuring tape was fitted around the infant's thigh, midway between the trochanterion and the tibiale laterale.
Length was measured with a calibrated seca 232 baby scales (seca GmbH \& Co., Birmingham, UK) with a measuring rod with integrated head and foot positioners. Infants were placed in a supine position with their head in contact with the head positioner and facing towards the ceiling in the Frankfort plane. A parent cupped each side of their infant's head, to ensure that the infant's head remained in the necessary position. Each infant's legs were gently straightened by the researcher and the foot positioner was moved up to the soles of their feet. A gentle downward pressure was exerted on the soles of each infant's feet to ensure that they were resting flat against the foot positioner. Three measurements were read to the nearest millimetre and the average of these three figures was recorded.

Infant weight was recorded using a scales attached to the PEA POD air displacement plethysmography system (COSMED, Surrey, UK). These scales were calibrated in kilograms to four decimal places. Weight was measured in line with manufacturer instructions and recorded.

\subsection{Measurement of infant body composition}

A PEA POD air displacement plethysmography (ADP) system (COSMED, Surrey, UK) assessed body composition (fat and fat-free mass). It is suitable for use in infants weighing between 1 and $8 \mathrm{~kg}$ and has been validated using doubly-labelled water [4,13-17]. ADP is a densitometric technique in which percentage body fat is determined by directly measuring subject mass and volume $[15,16]$. Mass is measured on an electronic scale; the infant wears no clothes or nappy during this measurement. An infant is then placed, without clothes or nappy, into a heated enclosed chamber. Infant volume is calculated by applying gas laws to the changes in air volume in the enclosed chamber [16]. Body density is computed from infant mass and volume, and is substituted into the two-compartment model to determine percentage body fat [16].

Body composition was measured in line with the manufacturer's (COSMED, Surrey, UK) instructions, where infants were placed lying down within the calibrated chamber of the machine for $90 \mathrm{~s}$. After $90 \mathrm{~s}$, body composition measurements for that infant were automatically sent to a computer attached to the device. These measurements were recorded by the first author.

\subsection{Statistical analysis}

Data analyses were performed using SPSS for Windows, version 24.0 (IBM, NY, USA). Statistical significance was taken at $p \leq 0.05$.

Normally distributed continuous data were summarised numerically using the mean and standard deviation (SD), and non-normally distributed continuous data were summarised using the median and interquartile range (IQR). Independent Samples $t$-tests were used for two group comparisons of normally distributed data. To compare differences in the mean scores of a dependent variable across three groups, a one-way between-groups analysis of variance (ANOVA) was conducted. Post-hoc comparisons were made using the Tukey HSD test. Normally distributed continuous data were correlated using the Pearson correlation.

Variables associated with percentage body fat in univariate analyses and/or in the scientific literature were included in multivariate analyses. Standard multiple regression predicted maternal characteristics independently associated with percentage body fat in infants at birth. Four categorical and two continuous variables were entered into the model. Preliminary analyses were conducted to ensure no violations of the assumptions of normality, linearity, multi-collinearity, and homoscedasticity. 
Table 1

Sociodemographic and health-related characteristics of the 196 participating women, and the 51 women who withdrew, or were withdrawn from, the study.

\begin{tabular}{|c|c|c|c|c|c|}
\hline & & \multicolumn{2}{|c|}{ Participating } & \multicolumn{2}{|c|}{ Withdrawn } \\
\hline & & \multicolumn{2}{|c|}{ Mean \pm SD } & \multicolumn{2}{|c|}{ Mean \pm SD } \\
\hline \multirow[t]{3}{*}{$\begin{array}{l}\text { Age at recruitment } \\
\text { BMI }\end{array}$} & $\begin{array}{l}\text { Years } \\
\mathrm{kg} / \mathrm{m}^{2}\end{array}$ & \multicolumn{2}{|c|}{$\begin{array}{l}31.2 \pm 5.1 \\
25.5 \pm 4.7\end{array}$} & \multicolumn{2}{|c|}{$\begin{array}{l}31.8 \pm 4.5 \\
25.4 \pm 4.3\end{array}$} \\
\hline & & \multicolumn{2}{|c|}{ Participating } & \multicolumn{2}{|c|}{ Withdrawn } \\
\hline & & $n$ & $\%$ & $n$ & $\%$ \\
\hline \multirow[t]{3}{*}{ Education level } & $\begin{array}{l}\text { Second-level } \\
\text { education }\end{array}$ & 52 & 26.5 & 12 & 23.5 \\
\hline & $\begin{array}{l}\text { Vocational } \\
\text { qualification }\end{array}$ & 24 & 12.2 & 9 & 17.6 \\
\hline & Third level degree & 120 & 61.2 & 30 & 58.8 \\
\hline \multirow[t]{5}{*}{ Social status } & Professional & 86 & 43.9 & 23 & 45.1 \\
\hline & Non-manual & 44 & 22.4 & 7 & 13.7 \\
\hline & Manual & 15 & 7.7 & 11 & 21.6 \\
\hline & Homemaker & 23 & 11.7 & 6 & 11.8 \\
\hline & Unknown & 28 & 14.3 & 4 & 7.8 \\
\hline \multirow[t]{2}{*}{ Material deprivation ${ }^{\mathrm{a}}$} & Yes & 103 & 52.6 & 13 & 25.5 \\
\hline & No & 93 & 47.4 & 38 & 74.5 \\
\hline \multirow[t]{2}{*}{ Health insurance } & No insurance & 139 & 70.9 & 36 & 70.6 \\
\hline & $\begin{array}{l}\text { Semi-private } \\
\text { insurance }\end{array}$ & 57 & 29.1 & 15 & 29.4 \\
\hline \multirow[t]{2}{*}{ Partner } & Has a partner & 189 & 96.4 & 48 & 94.1 \\
\hline & No partner & 7 & 3.6 & 3 & 5.9 \\
\hline \multirow[t]{2}{*}{ Family planning } & Planned pregnancy & 143 & 73.0 & 36 & 70.6 \\
\hline & Unplanned pregnancy & 53 & 27.0 & 15 & 29.4 \\
\hline \multirow[t]{4}{*}{ Pre-pregnancy BMI } & Underweight & 2 & 1.0 & 0 & 0.0 \\
\hline & Healthy weight & 98 & 50.0 & 27 & 52.9 \\
\hline & Overweight & 69 & 35.2 & 27 & 33.3 \\
\hline & Obese & 27 & 13.8 & 7 & 13.7 \\
\hline \multirow[t]{2}{*}{ Parity } & Primiparous & 82 & 41.8 & 18 & 35.3 \\
\hline & Multiparous & 114 & 58.2 & 33 & 64.7 \\
\hline \multirow[t]{2}{*}{ Gestational diabetes } & Yes & 5 & 2.6 & 0 & 0.0 \\
\hline & No & 191 & 97.4 & 51 & 100.0 \\
\hline \multirow[t]{2}{*}{$\begin{array}{l}\text { Folic acid } \\
\quad \text { supplementation }\end{array}$} & $\begin{array}{l}\text { Compliant with } \\
\text { recommendations }\end{array}$ & 65 & 33.2 & 18 & 35.3 \\
\hline & $\begin{array}{l}\text { Non-compliant with } \\
\text { recommendations }\end{array}$ & 131 & 66.8 & 33 & 64.7 \\
\hline \multirow[t]{4}{*}{ Smoking status } & Never smoked & 103 & 54.1 & 26 & 51.0 \\
\hline & $\begin{array}{l}\text { Ceased before } \\
\text { conception }\end{array}$ & 26 & 13.3 & 10 & 19.6 \\
\hline & $\begin{array}{l}\text { Ceased once } \\
\text { pregnancy confirmed }\end{array}$ & 43 & 21.9 & 9 & 17.6 \\
\hline & $\begin{array}{l}\text { All throughout } \\
\text { pregnancy }\end{array}$ & 21 & 10.7 & 6 & 11.8 \\
\hline \multirow[t]{2}{*}{ Alcohol consumption } & None in pregnancy & 153 & 78.1 & 40 & 78.4 \\
\hline & $\begin{array}{l}\text { Any alcohol in } \\
\text { pregnancy }\end{array}$ & 41 & 21.9 & 11 & 21.6 \\
\hline
\end{tabular}

SD: standard deviation; $\mathrm{kg} / \mathrm{m}^{2}$ : kilograms per metre squared; BMI: body mass index.

a As measured using the 11 deprivation indicators utilized by the European Union Survey on Income and Living Conditions (EU SILC).

\section{Results}

\subsection{Socio-demographic and health characteristics}

Two hundred and forty-seven women were recruited, and 196 (79.4\%) were eligible for inclusion in analysis. Fifty-one mothers were lost to follow-up in hospital due to the admission of an infant to intensive care ( $n 8)$, refusal of measurement in hospital (n14), or discharge before the researcher could approach for measurement (n29). Aside from length of gestation (those lost to follow-up had a significantly ( $p=0.05$ ) shorter gestation), the socio-demographic, health, and pregnancy characteristics of those who withdrew were not significantly different to those of women who continued to participate (Table 1).

The 196 participants included in analysis were $31.2 \pm 5.1$ years old and $29.9 \pm 6.0$ weeks pregnant at recruitment (Table 1). Participants were of Irish $(97.4 \%, n 191)$ or British $(2.6 \%, n 5)$ nationality. Three in five $(61.2 \%, n 120)$ had a college education. Over half $(58.2 \%, n 114)$ were employed full-time, with a further $14.3 \%$ ( $n 28)$ employed parttime, $15.8 \%$ ( $n 31)$ unemployed, and $11.7 \%$ (n23) being homemakers. Half $(52.6 \%, n 103)$ were experiencing some degree of material deprivation and most $(70.9 \%, n 139)$ had no health insurance.

Three in five $(58.2 \%, n 114)$ were on their second or subsequent pregnancy, and almost three-quarters $(73.0 \%, n 143)$ planned the pregnancy of interest to the study (Table 1$)$. One in five $(21.9 \%, n 43)$ consumed alcohol in pregnancy, drinking $2.3 \pm 2.0$ units alcohol per drinking occasion, and $78.1 \%$ ( $n 153)$ abstained from alcohol for the duration of pregnancy. Almost a third $(32.6 \%, n 64)$ smoked at some point in pregnancy, of which one in ten $(10.7 \%, n 21)$ smoked throughout all three trimesters. One percent (n2) had an underweight BMI, half $(50.0 \%, n 98)$ had a healthy BMI, a third $(35.2 \%, n 69)$ had an overweight BMI, and 13.8\% (n27) had an obese BMI.

\subsection{Birth and infant feeding characteristics}

Participants gave birth at $39.7 \pm 1.3$ weeks gestation. Over half $(51.5 \%, n 101)$ of the infants were female and a majority $(57.7 \%, n 113)$ of infants received breast milk as their first milk (Table 2). The median length of stay in hospital after labour was $48.2 \mathrm{~h}$, and by discharge, the rate of exclusive breastfeeding had decreased to less than a third $(32.1 \%, n 63)$.

\subsection{Anthropometric and body composition measures among infants}

Infants were a median of $27.5(18.0,40.9)$ hours old at measurement. The majority $(89.8 \%)$ of measurements were conducted within $48 \mathrm{~h}$, and the remaining within $72 \mathrm{~h}$. Mean percentage body fat among all infants was $10.3 \pm 3.7 \%$. Percentage body fat was significantly $(p=0.001)$ different between males and females, with males having significantly lower percentage body fat when compared to females (9.4 \pm 3.6 vs $11.1 \pm 3.7$, respectively) (Table 3). Percentage fat-free mass was also significantly $(p=0.001)$ different between males and females, with males having a higher percentage fat-free mass. Standard

Table 2

Birth-related and infant feeding characteristics of a sample of 196 mothers and infants.

\begin{tabular}{llll}
\hline & & $n$ & Median (IQR) \\
\hline Length of hospital stay & Hours & 196 & $48.2(33.4,71.6)$ \\
Age at measurement & Hours & 196 & $27.5(18.0,40.9)$
\end{tabular}

\begin{tabular}{llrr}
\hline & & $n$ & $\%$ \\
\hline \multirow{2}{*}{ Mode of delivery } & Vaginal delivery & 148 & 75.5 \\
& Caesarean section & 48 & 24.5 \\
Infant gender & Male & 95 & 48.5 \\
& Female & 101 & 51.5 \\
Birth weight category & Small for gestational age ( $\leq 9$ th centile) & 2 & 1.0 \\
& Appropriate for gestational age & 162 & 82.7 \\
& Large for gestational age ( $\geq 91$ st centile) & 32 & 16.3 \\
First milk & Breast milk & 113 & 57.7 \\
& Formula milk & 83 & 43.3 \\
Feeding at discharge & Exclusive breastfeeding & 63 & 32.1 \\
& Combination feeding & 27 & 13.8 \\
& Formula feeding & 106 & 54.1
\end{tabular}

IQR: interquartile range.

a Defined according to gender-specific UK-WHO Growth Charts 0-4 years (2009).

b Exclusive breastfeeding: the infant received only breast milk and no other liquids, with the exception of oral rehydration solution, vitamins and minerals, and medicines. Combination feeding: the infant received breast milk and formula milk. Formula feeding: the infant received only formula milk. 
Table 3

Mean anthropometric and body composition measurements of 196 infants at birth.

\begin{tabular}{|c|c|c|c|c|}
\hline & \multirow[t]{3}{*}{ Unit } & \multirow{2}{*}{$\frac{\text { Male }}{n 95}$} & \multirow{2}{*}{$\begin{array}{l}\text { Female } \\
n 101\end{array}$} & \multirow{2}{*}{$\begin{array}{l}\text { Total group } \\
n 196\end{array}$} \\
\hline & & & & \\
\hline & & Mean \pm SD & Mean \pm SD & Mean \pm SD \\
\hline Head circumference & $\mathrm{cm}$ & $35.3 \pm 1.3$ & $34.9 \pm 1.1$ & $35.1 \pm 1.2$ \\
\hline Chest circumference & $\mathrm{cm}$ & $33.5 \pm 1.8$ & $33.5 \pm 1.9$ & $33.5 \pm 1.9$ \\
\hline Abdominal circumference & $\mathrm{cm}$ & $32.7 \pm 1.9$ & $32.7 \pm 2.0$ & $32.7 \pm 1.9$ \\
\hline Mid-arm circumference & $\mathrm{cm}$ & $10.9 \pm 0.9$ & $10.8 \pm 1.1$ & $10.9 \pm 1.0$ \\
\hline Mid-thigh circumference & $\mathrm{cm}$ & $14.6 \pm 1.3$ & $14.5 \pm 1.4$ & $14.5 \pm 1.4$ \\
\hline Length & $\mathrm{cm}$ & $51.8 \pm 2.1$ & $50.5 \pm 1.9$ & $51.1 \pm 2.1$ \\
\hline Weight & $\mathrm{g}$ & $3446.1 \pm 472.1$ & $3335.5 \pm 432.9$ & $3389.1 \pm 454.5$ \\
\hline \multirow[t]{2}{*}{ Fat-free mass } & $\mathrm{g}$ & $3114.5 \pm 379.9$ & $2965.1 \pm 346.7$ & $3037.5 \pm 369.9$ \\
\hline & $\%$ & $90.6 \pm 3.7$ & $88.9 \pm 3.7$ & $89.7 \pm 3.8$ \\
\hline \multirow[t]{2}{*}{ Fat mass } & $\mathrm{g}$ & $330.7 \pm 151.3$ & $380.3 \pm 155.6$ & $345.3 \pm 155.2$ \\
\hline & $\%$ & $9.4 \pm 3.6$ & $11.1 \pm 3.7$ & $10.3 \pm 3.7$ \\
\hline Ponderal index ${ }^{\mathrm{a}}$ & & $2.58 \pm 0.22$ & $2.68 \pm 0.21$ & $2.63 \pm 0.22$ \\
\hline
\end{tabular}

SD: standard deviation; $\mathbf{c m}$ : centimetres; g: grams.

a Calculated as [weight (grams) $* 100 /$ length $^{3}$ (centimetres)].

Statistically significant $(p=0.001)$ difference between percentage fat and fat-free mass in males and females observed by an Independent Samples $t$-test.

anthropometric measurements did not significantly differ between male and female infants (Table 3).

\subsection{Maternal characteristics associated with percentage body fat at birth}

For the purpose of analyses, the two participants with an underweight pre-pregnancy BMI were included in the healthy pre-pregnancy BMI category. This amalgamation did not change the original mean of the healthy BMI category. In univariate analyses (Table 4), maternal social class, parity, smoking throughout pregnancy, and pre-pregnancy BMI were significantly associated with percentage body fat in an infant at birth. Although not shown in a table, maternal age and percentage body fat in the infant were not significantly associated with one another ( $p=0.763$ ). In the multivariate regression model (Table 5), maternal social class, parity, and pre-pregnancy BMI were significant independent predictors of percentage body fat at birth.

Percentage body fat was significantly lower in infants born to women of low social class, when compared to infants born to women of middle or high social class $(8.2 \pm 3.8,10.8 \pm 3.7$, and $10.4 \pm 3.5$, respectively, Table 4). There was no significant difference in the percentage body fat between infants born to women of middle and high social class. In multivariate analyses (Table 5), infants born to women of middle and high social class had $2.34 \pm 0.78 \%$ higher percentage body fat compared to those born to women of low social class $(p=0.003)$.

Primiparous women gave birth to infants with significantly lower percentage body fat, when compared to multiparous women ( $9.7 \pm 4.0$ and $10.7 \pm 3.5$, respectively, Table 4$)$. This trend was also seen in multivariate analyses (Table 5), where infants born to primiparous women had $1.36 \pm 0.53 \%$ lower percentage body fat compared to those born to multiparous women $(p=0.011)$.

Percentage body fat was significantly $(p=0.004)$ higher in infants born to women with an obese or overweight BMI, when compared to infants born to women with a healthy BMI (12.1 \pm 4.0, $11.1 \pm 3.1$, and $9.2 \pm 3.7$, respectively, Table 4). There was no significant difference in the percentage body fat of infants born to women with an obese or overweight BMI. A significant positive correlation $(p=0.01$, $r=0.294$ ) was observed between maternal BMI and percentage body fat in the infant, where percentage body fat in the infant increased as maternal BMI increased (Fig. 1). As shown in Fig. 1, among the total sample, the percentage body fat of infants born to women with an overweight or obese BMI was $17.1 \%$ and $23.9 \%$ higher, respectively, than the percentage body fat of infants born to women with a healthy weight BMI. This trend was also seen in multivariate analyses (Table 5), where percentage body fat in the infant increased by $0.21 \pm 0.05 \%$ for every unit increase of maternal BMI $(p<0.001)$.

\section{Discussion}

The optimisation of growth in utero may attenuate the risk of adverse health outcomes over the life course [5,23-25], and body composition in particular is an aspect of infant growth that has become a topic of scrutiny in recent years. In this study, percentage body fat was significantly lower in infants born to mothers of low social class and to primiparous mothers, and was significantly higher in infants born to mothers who had an overweight or obese BMI prior to pregnancy. In light of the plasticity of growth in utero, and how sensitive this period is to care and insult alike, continued investigation into factors that promote positive health outcomes from the earliest stages of development is essential.

As maternal pre-pregnancy BMI increased in this study, so too did percentage body fat in offspring. The infants born to women with an overweight or obese pre-pregnancy BMI had significantly higher percentage body fat when compared to infants born to women with a healthy pre-pregnancy BMI; a finding consistently reported by the literature $[1,6,12,26]$. Given that a mother provides genes and the intrauterine environment in which a foetus develops, it is expected that an infant's physical condition at birth will reflect the exposures, and physical condition, of their mother during pregnancy [27]. A consequence of this is that an infant may be predisposed to obesity from the earliest stages of development $[2,9,11]$, thus making maternal overweight an important and potentially modifiable risk factor for undesirable weight gain in infancy [2,3] and childhood [5,25].

Many studies have investigated factors that promote healthy weight gain during pregnancy [28-30], but no studies to date have published results on helping women planning a pregnancy to attain a healthy BMI prior to conception. One clinical trial in this area is underway [31], but this area would benefit from further investigation [12]. Similar to nationally representative figs. [32], a quarter of pregnancies in this study were unplanned. Although a sizeable minority of pregnancies remain unplanned, the majority of women do plan their pregnancies. Therefore, it is worthwhile to impress upon all women of childbearing age the importance of attaining and maintaining a healthy weight. Additionally, appropriate interventions to help couples planning a pregnancy to optimise their weight status prior to conceiving are needed [28,33-36].

Low social class was associated with lower percentage body fat at birth in this study. Low social class and its associated economic and 
Table 4

Maternal characteristics associated with percentage body fat in 196 infants at birth.

\begin{tabular}{|c|c|c|c|}
\hline \multirow[t]{2}{*}{ Characteristic } & \multicolumn{2}{|c|}{$\%$ body fat in infant at birth } & \multirow[t]{2}{*}{$p$-Value* } \\
\hline & $n$ & Mean $\pm S D$ & \\
\hline \multicolumn{4}{|l|}{ Maternal education } \\
\hline Third-level education & 76 & $9.9 \pm 3.4$ & \\
\hline No third-level education & 120 & $10.5 \pm 3.9$ & $0.27^{\mathrm{a}}$ \\
\hline \multicolumn{4}{|l|}{ Maternal social class } \\
\hline High & 86 & $10.4 \pm 3.5$ & \\
\hline Middle & 82 & $10.8 \pm 3.7^{\circ}$ & \\
\hline Low & 28 & $8.2 \pm 3.8$ & $0.004^{\mathrm{b}}$ \\
\hline \multicolumn{4}{|l|}{ Parity } \\
\hline Primiparous & 82 & $9.7 \pm 4.0$ & $0.05^{\mathrm{a}}$ \\
\hline Multiparous & 114 & $10.7 \pm 3.5$ & \\
\hline \multicolumn{4}{|l|}{ Maternal body mass index } \\
\hline Healthy $\left(18.5-25.0 \mathrm{~kg} / \mathrm{m}^{2}\right)$ & 100 & $9.2 \pm 3.7$ & $<0.001^{\mathrm{b}}$ \\
\hline Overweight $\left(25.1-29.9 \mathrm{~kg} / \mathrm{m}^{2}\right)$ & 69 & $11.1 \pm 3.1$ & \\
\hline Obese $\left(\geq 30.0 \mathrm{~kg} / \mathrm{m}^{2}\right)$ & 27 & $12.1 \pm 4.0^{\circ}$ & \\
\hline \multicolumn{4}{|l|}{ Gestational diabetes } \\
\hline Present & 5 & $13.1 \pm 4.5$ & $0.08^{\mathrm{a}}$ \\
\hline Absent & 191 & $10.2 \pm 3.7$ & \\
\hline \multicolumn{4}{|l|}{ Any smoking in pregnancy } \\
\hline Yes & 64 & $10.0 \pm 3.8$ & $0.41^{\mathrm{a}}$ \\
\hline No & 132 & $10.4 \pm 3.7$ & \\
\hline \multicolumn{4}{|l|}{ Smoked in all three trimesters } \\
\hline Yes & 21 & $8.7 \pm 3.8$ & $0.04^{\mathrm{a}}$ \\
\hline No & 175 & $10.5 \pm 3.7$ & \\
\hline \multicolumn{4}{|l|}{ Any alcohol in pregnancy } \\
\hline Yes & 43 & $9.5 \pm 4.5$ & $0.14^{\mathrm{a}}$ \\
\hline No & 153 & $10.5 \pm 3.5$ & \\
\hline \multicolumn{4}{|l|}{ Material deprivation in pregnancy } \\
\hline Yes & 103 & $9.9 \pm 3.7$ & $0.16^{\mathrm{a}}$ \\
\hline No & 93 & $10.7 \pm 3.7$ & \\
\hline
\end{tabular}

a Association between normally distributed continuous data and one categorical independent variable (with two levels) assessed using an Independent Samples $t$-test.

b Association between normally distributed continuous data and one categorical independent variable (with three levels) assessed using a one-way between groups ANOVA.

${ }^{*} p$-Value $<0.05$ was significant; SD: Standard deviation; $\mathbf{k g} / \mathrm{m}^{2}$ : kilogram per metre squared.

Statistically significant difference between two mean values identified using the Tukey HSD test.

Statistically significant difference between two mean values identified using the Tukey HSD test.

educational disadvantage have been linked with low birth weight in other studies, but not necessarily lower adiposity [34,37,38]. Although research has shown an inverse relationship between low birth weight and obesity risk in childhood $[34,38]$, the relationship between a lower percentage body fat and later obesity risk is unclear. However, low social class is one of a cluster of socioeconomic characteristics that may precipitate health inequality in offspring [38], and so the impact of socioeconomic disadvantage on adiposity at birth and consequent health outcomes is worthy of further investigation. Primiparity was also associated with lower percentage body fat at birth in this study. Increasing parity has been associated with increased adiposity in offspring in the literature [39], and whilst the pathway remains to be fully elucidated, maternal nutritional, cardiovascular, or immunologic mechanisms have been implicated in this association [39].

Infant body composition is a burgeoning area of research, and work remains to be done to determine optimum levels of percentage body fat in term infants at birth [40], in addition to determining long-term consequences associated with a percentage body fat at birth that exceeds normative values [18].
Table 5

Standard regression model of maternal characteristics independently associated with percentage body fat at birth in a sample of 196 singleton infants.

\begin{tabular}{|c|c|c|c|c|c|c|}
\hline & & $n$ & $\beta$ & Std error & $95 \%$ CI for $\beta$ & $p$-Value* \\
\hline $\begin{array}{l}\text { Maternal third } \\
\quad \text { level } \\
\text { education }\end{array}$ & & & & & & 0.279 \\
\hline Yes & Ref. & 120 & +0.57 & 0.53 & $-0.47-1.62$ & \\
\hline No & & 76 & & & & \\
\hline Parity & & & & & & 0.011 \\
\hline $\begin{array}{l}\text { Multiparous } \\
\text { Smoked in all } \\
\text { three } \\
\text { trimesters }\end{array}$ & & 114 & & & & 0.252 \\
\hline No & Ref. & 175 & +0.94 & 0.82 & $-0.68-2.56$ & \\
\hline Yes & & 21 & & & & \\
\hline Social class & & & & & & 0.003 \\
\hline $\begin{array}{l}\text { Middle or high } \\
\text { Low }\end{array}$ & Ref. & $\begin{array}{r}168 \\
28\end{array}$ & +2.34 & 0.78 & $0.81-3.87$ & \\
\hline $\begin{array}{l}\text { Maternal BMI (kg/ } \\
\left.\mathrm{m}^{2}\right)\end{array}$ & & 196 & +0.21 & 0.05 & $0.10-0.31$ & $<0.001$ \\
\hline $\begin{array}{c}\text { Maternal age } \\
\text { (years) }\end{array}$ & & 196 & -0.09 & 0.06 & $-0.21-0.26$ & 0.128 \\
\hline
\end{tabular}

Model summary: $\mathrm{R}^{2}=0.174$, Adjusted R Square $=0.147$.

CI: Confidence interval.

$\mathrm{kg} / \mathrm{m}^{2}$ : kilograms per metre squared.

${ }^{*} p$-Value $<0.05$ was significant.

Investigation into how to manage an elevated percentage body fat in an infant at birth would be worthwhile, as would studies on measures that prevent an elevated percentage body fat at birth.

\subsection{Strengths and limitations}

All data were collected solely by the first author, who was trained in the collection of infant anthropometric measures, thus minimising intra-observer error and eliminating inter-observer error [41,42]. Anthropometric measurements obtained on infants at birth in this study were comparable to measurements reported in nationally representative studies $[18,25,43]$. The mean birth weight of infants in this study, at $3.55 \mathrm{~kg}$, compares favourably to nationally representative figures of $3.47 \mathrm{~kg}$ [43] and $3.50 \mathrm{~kg}$ [18]. The average birth length in this study, at $51.2 \mathrm{~cm}$, was similar to the nationally representative figure of $50.9 \mathrm{~cm}$ for infants born at 40 weeks gestation [18]. Percentages of body fat at birth among males, females and the full sample were $9.4 \%, 11.1 \%$ and $10.3 \%$, respectively, and were obtained using a recognised gold-standard technique [26,44]. These measures reflect normative values elucidated by a large Irish study [18], where percentages of body fat at birth among males, females and both genders together were $9.8 \%, 11.9 \%$ and $10.8 \%$, respectively. Therefore, the anthropometric measures recorded at birth in this study form a reliable baseline for comparison of outcomes.

However, the study is not nationally representative, and, being an observational study based on a convenience sample, causal inferences cannot be made [45]. Reliable estimates of gestational weight gain and post-partum BMI were not available; gestational weight gain is associated with adiposity at birth $[3,23]$ and should be consistently recorded in future research studies on this topic.

\section{Conclusion}

Health interventions and public health policies play a valuable and necessary role in promoting healthy foetal development. This study is one of the first to investigate maternal characteristics associated with percentage body fat in offspring using a gold standard technique in an Irish setting. It echoes the international literature on the relationship between maternal BMI and the body composition of offspring at birth. It 


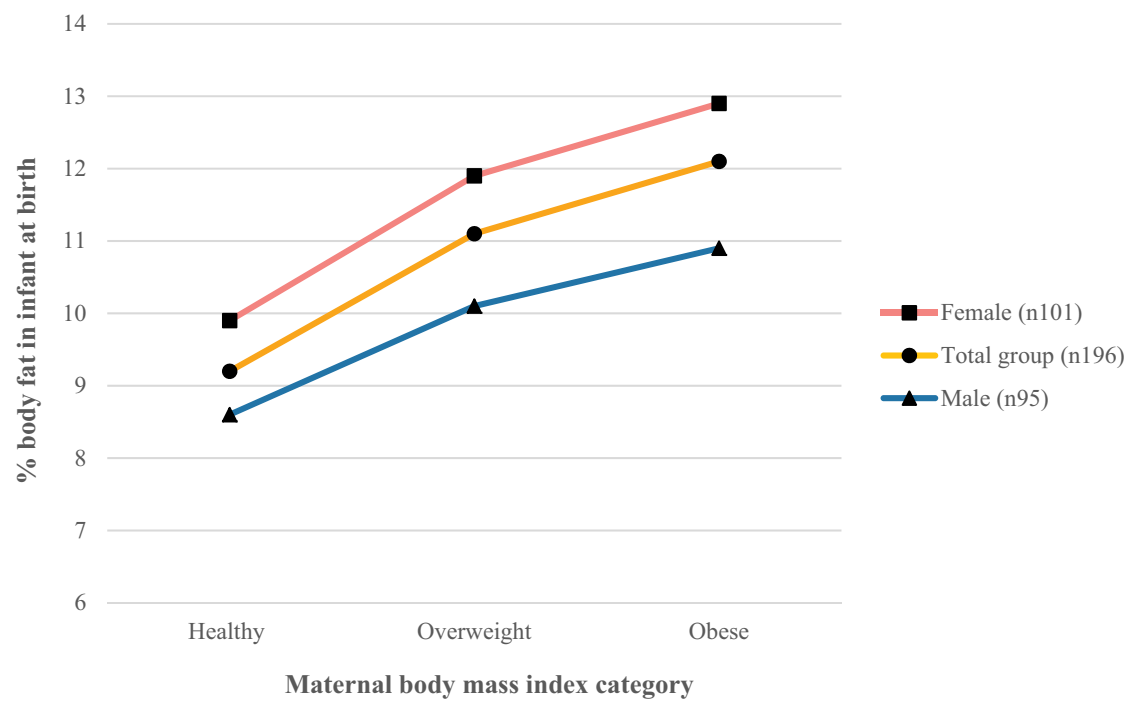

Fig. 1. Relationship between maternal body mass index and percentage fat mass in 196 singleton infants at birth.

highlights the need to devise interventions that enable couples planning a pregnancy to attain and maintain a healthy weight prior to conceiving, and it also emphasises the importance of investigating the medium- and long- term consequences of a percentage body fat at birth that exceeds normative values. Since the growth and adiposity of an infant are so closely tied to a mother's health long before the birth, and even conception, of her infant, continued investigation into effective approaches that promote good physical wellbeing among all women, and particularly those planning a family, is warranted.

\section{Declaration of competing interest}

The authors have no conflict of interest to declare.

\section{Acknowledgements}

The authors wish to acknowledge the time of all those who participated in this study.

\section{Funding}

A.E. Bennett was supported by a Dublin Institute of Technology Fiosraigh Scholarship, which is equally funded by Dublin Institute of Technology and Danone Nutricia Early Life Nutrition. Danone Nutricia had no role in the: study design; collection, analysis, and interpretation of data; writing of the manuscript; and decision to submit the manuscript for publication.

A.E. Bennett was responsible for the study design, data collection, data analysis, drafting the manuscript, and making amendments to the manuscript. J.M Kearney was the study supervisor and assisted with drafting and revising the manuscript.

\section{References}

[1] P.M. Catalano, A. Thomas, L. Huston-Presley, S.B. Amini, Increased fetal adiposity: a very sensitive marker of abnormal in utero development, Am. J. Obstet. Gynecol. 189 (2003) 1698-1704.

[2] M.F. Sewell, L. Huston-Presley, D.M. Super, P. Catalano, Increased neonatal fa mass, not lean body mass, is associated with maternal obesity, Am. J. Obstet. Gynecol. 195 (2006) 1100-1103.

[3] L. Pereira-da-Silva, C. Cabo, A.C. Moreira, D. Virella, T. Guerra, T. Camoes, A.R. Silva, R. Neves, G.C. Ferreira, The adjusted effect of maternal body mass index, energy and macronutrient intakes during pregnancy, and gestational weight gain on body composition of full-term neonates, Am. J. Perinat. 31 (2014) 875-882.

[4] G. Ma, M. Yao, Y. Liu, A. Lin, H. Zou, A. Urlando, W.W. Wong, L. Nommsen-Rivers, K.G. Dewey, Validation of a new pediatric air-displacement plethysmograph for assessing body composition in infants, Am. J. Clin. Nutr. 79 (2004) 653-660.

[5] K.V. Dalrymple, J.M.D. Thompson, S. Begum, K.M. Godfrey, L. Poston, P.T. Seed, L.M.E. McCowan, C. Wall, A. Shelling, R. North, W.S. Cutfield, E.A. Mitchell, Relationships of maternal body mass index and plasma biomarkers with childhood body mass index and adiposity at 6 years: the children of SCOPE study, Pediatr. Obes. 14 (10) (2019) e12537.

[6] C. Hellmuth, K.L. Lindsay, O. Uhl, C. Buss, P.D. Wadhwa, B. Koletzko, S. Entringer, Association of maternal prepregnancy BMI with metabolomic profile across gestation, Int. J. Obesity. 41 (2017) 159-169.

[7] C. Hellmuth, K.L. Lindsay, O. Uhl, C. Buss, P.D. Wadhwa, B. Koletzko, S. Entringer, Maternal metabolomic profile and fetal programming of offspring adiposity: identification of potentially protective lipid metabolites, Mol. Nutr. Food Res. 63 (2019) e1700889.

[8] L. Wang, A. van Grieken, J. Yang-Huang, E. Vlasblom, M.P. L'Hoir, M.M. BoereBoonekamp, H. Raat, Relationship between socioeconomic status and weight gain during infancy: the BeeBOFT study, PLoS One 13 (2018) e0205734.

[9] S. Timur Tashan, N. Hotun Sahin, M. Omac Sonmez, Maternal smoking and newborn sex, birth weight and breastfeeding: a population-based study, J. Matern-Fetal. Neo. M. 30 (2017) 2545-2550.

[10] S. Heinz-Partington, G. Condous, M. Mongelli, Differential effects of cigarette smoking on birth weight by maternal body mass index, J. Obstet. Gynecol. 36 (2016) 608-610.

[11] D.K. Longmore, E.L.M. Barr, I.L. Lee, F. Barzi, M. Kirkwood, C. Whitbread, V. Hampton, S. Graham, P. Van Dokkum, C. Connors, J.A. Boyle, P. Catalano, A.D.H. Brown, K. O'Dea, J. Oats, H.D. McIntyre, J.E. Shaw, L.J. Maple-Brown, Maternal body mass index, excess gestational weight gain, and diabetes are positively associated with neonatal adiposity in the Pregnancy and Neonatal Diabetes Outcomes in Remote Australia (PANDORA) study, Pediatr. Obes. 14 (2019) e12490.

[12] N. Heslehurst, R. Vieira, Z. Akhter, H. Bailey, E. Slack, L. Ngongalah, A. Pemu, J. Rankin, The association between maternal body mass index and child obesity: a systematic review and meta-analysis, PLoS Med. 16 (2019) e1002817.

[13] K.J. Ellis, M. Yao, R.J. Shypailo, A. Urlando, W.W. Wong, W.C. Heird, Body-composition assessment in infancy: air-displacement plethysmography compared with a reference 4-compartment model, Am. J. Clin. Nutr. 85 (2007) 90-95.

[14] R.D. Sainz, A. Urlando, Evaluation of a new pediatric air-displacement plethysmograph for body-composition assessment by means of chemical analysis of bovine tissue phantoms, Am. J. Clin. Nutr. 77 (2003) 364-370.

[15] A. Urlando, P. Dempster, S. Aitkens, A new air displacement plethysmograph for the measurement of body composition in infants, Pediatr. Res. 53 (2003) 486-492.

[16] M. Yao, L. Nommsen-Rivers, K. Dewey, A. Urlando, Preliminary evaluation of a new pediatric air displacement plethysmograph for body composition assessment in infants, Acta Diabetol. 40 (Suppl. 1) (2003) S55-S58.

[17] P.M. Catalano, N.M. Drago, S.B. Amini, Factors affecting fetal growth and body composition, Am. J. Obstet. Gynecol. 172 (1995) 1459-1463.

[18] C.P. Hawkes, J.O. Hourihane, L.C. Kenny, A.D. Irvine, M. Kiely, D.M. Murray, Gender- and gestational age-specific body fat percentage at birth, Pediatrics 128 (2011) e645-e651.

[19] World Health Organisation, Obesity: preventing and managing the global epidemic, Report of a WHO Consultation. World Health Organization Technical Report Series, vol. 894, 2000, pp. 1-253.

[20] B. Thomas, J. Bishop, Manual of Dietetic Practice, 4th ed., (2007).

[21] T.S. Usha Kiran, S. Hemmadi, J. Bethel, J. Evans, Outcome of pregnancy in a woman with an increased body mass index, BJOG. Int. J. Obstet. Gy. 112 (2005) $768-772$

[22] C. Fattah, N. Farah, S.C. Barry, N. O'Connor, B. Stuart, M.J. Turner, Maternal weight and body composition in the first trimester of pregnancy, Acta. Obst. Gyn. Scan. 89 (2010) 952-955. 
[23] D.L. Dahly, X. Li, H.A. Smith, A.S. Khashan, D.M. Murray, M.E. Kiely, F.P. McCarthy, L.C. Kenny, P.M. Kearney, Associations between maternal lifestyle factors and neonatal body composition in the Screening for Pregnancy Endpoints (Cork) cohort study, Int. J. Epidemiol. 47 (2018) 131-145.

[24] A.E. Bennett, C. Johnston Molloy, C. Glennon-Slattery, D. Loane, Outcomes of a community-based paediatric weight management programme in an Irish midlands setting, Ir. Med. J. 111 (2018) 689.

[25] R. Layte, A.E. Bennett, C. McCrory, J. Kearney, Social class variation in the predictors of rapid growth in infancy and obesity at age 3 years, Int. J. Obesity. 38 (2014) 82-90.

[26] C.P. Au, C.H. Raynes-Greenow, R.M. Turner, A.E. Carberry, H. Jeffery, Fetal and maternal factors associated with neonatal adiposity as measured by air displacement plethysmography: a large cross-sectional study, Early Hum. Dev. 89 (2013) 839-843.

[27] A.M. Dattilo, L. Birch, N.F. Krebs, A. Lake, E.M. Taveras, J.M. Saavedra, Need for early interventions in the prevention of pediatric overweight: a review and upcoming directions, J. Obes. 2012 (2012) 123023.

[28] R.R.C. McEachan, G. Santorelli, M. Bryant, P. Sahota, D. Farrar, N. Small, S. Akhtar, J. Sargent, S.E. Barber, N. Taylor, G. Richardson, A.J. Farrin, R.S. Bhopal, D.D. Bingham, S.M. Ahern, J. Wright, The HAPPY (Healthy and Active Parenting Programmme for early Years) feasibility randomised control trial: acceptability and feasibility of an intervention to reduce infant obesity, BMC Public Health 16 (2016) 211.

[29] R.S. Opie, M. Neff, A.C. Tierney, A behavioural nutrition intervention for obese pregnant women: effects on diet quality, weight gain and the incidence of gestational diabetes, Aust. N. Z. J. Obstet. Gynaecol. 56 (2016) 364-373.

[30] P. van der Pligt, K. Campbell, J. Willcox, J. Opie, E. Denney-Wilson, Opportunities for primary and secondary prevention of excess gestational weight gain: general Practitioners' perspectives, BMC Fam. Pract. 12 (2011) 124.

[31] F.S. LeBlanc, K.K. Vesco, K.L. Funk, N. Karanja, N. Smith, V.J. Stevens, Prepare, a randomized trial to promote and evaluate weight loss among overweight and obese women planning pregnancy: study design and rationale, Contemp. Clin. Trials. 49 (2016) 174-180.

[32] S. Sheehan, Annual Clinical Report, Coombe Women and Infants University Hospital, Dublin, 2017, p. 62.

[33] A.E. Bennett, J.M. Kearney, Factors associated with maternal wellbeing at four months post-partum in Ireland, Nutrients 10 (2018).

[34] G.F. McLeod, D.M. Fergusson, L.J. Horwood, J.M. Boden, F.A. Carter, Childhood predictors of adult adiposity: findings from a longitudinal study, N. Z. Med. J. 131 (2018) 10-20.

[35] A.E. Bennett, D. McCartney, J.M. Kearney, Views of fathers in Ireland on the experience and challenges of having a breast-feeding partner, Midwifery 40 (2016) 169-176.

[36] T.A. Hagobian, S. Phelan, A.A. Gorin, M.G. Phipps, B. Abrams, R.R. Wing, Effects of maternal lifestyle intervention during pregnancy on untreated partner weight: results from fit for delivery study, Obesity 24 (2016) 23-25.

[37] G.E. Miller, J. Culhane, W. Grobman, H. Simhan, D.E. Williamson, E.K. Adam, C. Buss, S. Entringer, K.Y. Kim, J. Felipe Garcia-Espana, L. Keenan-Devlin, T.W. McDade, P.D. Wadhwa, A. Borders, Mothers' childhood hardship forecasts adverse pregnancy outcomes: role of inflammatory, lifestyle, and psychosocial pathways, Brain Behav. Immun. 65 (2017) 11-19.

[38] C.S. Morgen, P.K. Andersen, L.H. Mortensen, L.D. Howe, M. Rasmussen, P. Due, T.I. Sorensen, A.N. Andersen, Socioeconomic disparities in birth weight and body mass index during infancy through age 7 years: a study within the Danish National Birth Cohort, BMJ Open 7 (2017) e011781.

[39] N.P. Joshi, S.R. Kulkarni, C.S. Yajnik, C.V. Joglekar, S. Rao, K.J. Coyaji, H.G. Lubree, S.S. Rege, C.H. Fall, Increasing maternal parity predicts neonatal adiposity: pune maternal nutrition study, Am. J. Obstet. Gynecol. 193 (2005) 783-789.

[40] E.W. Demerath, W. Johnson, B.A. Davern, C.G. Anderson, J.S. Shenberger, S. Misra S.E. Ramel, New body composition reference charts for preterm infants, Am. J. Clin. Nutr. 105 (2017) 70-77.

[41] M. Arroyo, M. Freire, L. Ansotegui, A.M. Rocandio, Intraobserver error associated with anthropometric measurements made by dietitians, Nutr. Hosp. 25 (2010) 1053-1056.

[42] S.J. Ulijaszek, D.A. Kerr, Anthropometric measurement error and the assessment of nutritional status, Brit. J. Nutr. 82 (1999) 165-177.

[43] R. Layte, C. McCrory, Growing up in Ireland: Maternal Health Behaviours and Child Growth in Infancy, The Stationary Office, Dublin, Department of Children and Youth Affairs, 2014, pp. 53-64.

[44] H. Mazahery, P.R. von Hurst, C.J.D. McKinlay, B.E. Cormack, C.A. Conlon, Air displacement plethysmography (pea pod) in full-term and pre-term infants: a comprehensive review of accuracy, reproducibility, and practical challenges, Matern. Health. Neonatol. Perinatol. 4 (2018) 12.

[45] D.A. Grimes, K.F. Schulz, An overview of clinical research: the lay of the land, Lancet 359 (2002) 57-61. 